\title{
Desigualdad global y migración calificada de México a Estados Unidos
}

\author{
Telésforo Ramírez García* \\ Fernando Lozano Ascencio**
}

Recepción: 7 de abril de 2017 Aceptación: 17 de julio de 2017

Resumen El incremento de la población calificada como migrante en Estados Unidos no necesariamente significa que sus condiciones de trabajo y de vida sean similares a las de la población nativa. Se trata, en rigor, de una incorporación caracterizada por la desigualdad en cuanto a sus condiciones de participación económica, política y social. Tomando este hecho como punto de partida, el objetivo de este artículo es examinar las desigualdades sociodemográficas y sociolaborales de la población migrante calificada residente en Estados Unidos en el arranque del presente siglo, específicamente entre 2003 y 2015. El trabajo compara las características sociodemográficas y laborales de la población nativa de Estados Unidos con las de la población migrante de Europa y Canadá, Asia, México y Latinoamérica y el Caribe. Destaca principalmente el caso de los migrantes mexicanos y hace comparaciones con otros grupos de inmigrantes. La fuente de información empleada es la Encuesta Nacional de Graduados Universitarios (National Survey of College Graduates, NSCG), que incluye a la población con estudios universitarios residente en Estados Unidos, con al menos una licenciatura y hasta 75 años de edad. El propósito final del artículo es ofrecer elementos que contribuyan a revalorar la presencia de la población migrante en la fuerza laboral de Estados Unidos, particularmente entre la población con estudios universitarios.

\section{PALABRAS CLAVE: desigualdad global, migración calificada, fuga de cerebros, México-Estados} Unidos.

Abstract The growth of a highly-skilled migrant population in the United States does not necessarily mean that their working and living conditions are similar to those of the native population. It is, strictly speaking, an incorporation characterized by inequality, in terms of their conditions of

*Catedrático Conacyt del CRIM-UnAm, telex33@gmail.com

**Investigador del CRIM-UNAM, flozano@correo.crim.unam.mx 
economic, political and social participation. Considering this fact as a starting point, the aim of this article is to examine the sociodemographic and labor inequalities of the highly skilled migrant population residing in the United States, between 2003 and 2015. The study compares the sociodemographic and labor characteristics of the native population of the United States to those of migrant populations from Europe and Canada, Asia, Mexico, and Latin America and the Caribbean. It highlights the case of Mexican migrants and makes comparisons with other groups of immigrants. The data comes from the National Survey of College Graduates (NSCG), which includes the population of college graduates who live in the United States, with at least a bachelor's degree and up to 75 years of age. The final purpose of the article is to offer elements that contribute to revaluing the presence of the migrant population in the United States labor force, particularly among the population with graduate studies.

KEY WORDS: global inequality, highly-skilled migration, brain drain, Mexico-United States.

\section{Introducción}

sí como el proceso de globalización ha significado un incremento genera-
lizado de la riqueza, también ha contribuido a acrecentar las desigualdades
económicas y sociales entre países y en el interior de estos, lo que se expresa en una mayor concentración de la riqueza generada, un incremento de la polarización social y un aumento de la movilidad humana del Sur al Norte global. Una de las manifestaciones más directas de esta globalización neoliberal en la movilidad humana es precisamente la proliferación de todo tipo de restricciones a la migración de mano de obra de baja escolaridad o calificación, frente al impulso de políticas que favorecen la migración de mano de obra más calificada y especializada. En ese sentido, la movilidad humana es también más desigual, más selectiva, pues se dificulta o favorece el desplazamiento de las personas según su escolaridad, calificación laboral, nacionalidad, raza, etnia o sexo.

Históricamente, la emigración altamente calificada ha sido un motor para la innovación, la creación de empleo y el aumento del nivel de vida en las sociedades receptoras. Esta migración ha desempeñado un papel central en ayudar a las empresas del Norte global a satisfacer su creciente demanda de mano de obra calificada -que está creciendo mucho más rápidamente que la oferta-, lo que está ayudando a las empresas a soportar una "crisis de talento" (Hanson \& Slaughter, 2013; Peri, 2017). 
El incremento de la población calificada migrante en los países de destino no necesariamente significa que sus condiciones de trabajo y de vida sean similares a las de la población nativa de los países receptores. Se trata, en rigor, de una experiencia caracterizada por la desigualdad en cuanto a sus condiciones de inserción y participación económica, política y social. De acuerdo con Cairns, Cuzzocrea, Briggs \& Veloso, (2017), existen migrantes calificados que podrían ser considerados como "ganadores", para quienes la libertad de moverse a través de las fronteras se ha convertido en parte integral de su vida social, económica, política y cultural. Se trata de un sector que se incorpora de manera competitiva e incluyente en los países de destino. Sin embargo, existe un sector de migrantes menos favorecidos, con capacidad de circulación restringida, que enfrentan procesos de exclusión social debido a circunstancias socioestructurales, ya sea por falta de capital social, económico y cultural o por características más individuales, como el origen nacional, la raza o el sexo (véase también Cheng \& Yang, 1998).

De acuerdo con la teoría clásica de la asimilación, la población migrante sigue una pauta de convergencia con la población nativa y se hace más similar a lo largo del tiempo en normas, valores, comportamientos y características. Para esta teoría, los inmigrantes que residen más tiempo en la sociedad de acogida, así como los miembros de generaciones posteriores, muestran mayores similitudes con el grupo mayoritario que los inmigrantes que han estado menos tiempo en el país receptor (Brown \& Bean, 2006). No obstante, la experiencia histórica de la emigración a los países del Norte global, y específicamente a Estados Unidos, da cuenta de las profundas desigualdades en los procesos de asimilación o incorporación económica y social de la población migrante, que son mediados por la existencia de políticas salariales discriminatorias e incluso por criterios racistas.

La gran paradoja es que países como Estados Unidos, que despliegan un conjunto de políticas migratorias orientadas a reclutar a "los mejores y más brillantes" profesionistas de otros países, con el propósito de garantizar su crecimiento económico y el desarrollo de su planta productiva, mantienen políticas que favorecen el trabajo temporal, de mano de obra flexible o desechable, o con esquemas precarios de incorporación laboral, como es el caso de los programas de "entrenamiento" para estudiantes extranjeros egresados de universidades norteamericanas. Se trata de un reclutamiento "interno" de estudiantes extranjeros egresados de sus propias universidades para mantenerlos como trabajadores "externos" (Cairns, et al., 2017).

La posesión o no de la ciudadanía del país de acogida, el contar o no con la certificación oficial de las credenciales educativas y el contar con los permisos correspondientes para permanecer de manera temporal o definitiva en el país de destino son solo algunos de los aspectos que propician la desigualdad en la incorporación de la población migrante y que, en el caso de la población de origen mexicano en Estados Unidos, han tenido un impacto sumamente desfavorable y la ubican en los 
niveles más bajos de la estructura ocupacional con trabajos precarios, bajos salarios y en ocupaciones que no se corresponden con su educación formal (Ramírez \& Lozano, 2017).

El objetivo de este artículo es examinar las desigualdades sociodemográficas y sociolaborales de la población migrante calificada (con estudios de licenciatura terminada, grado profesional o posgrado) residente en Estados Unidos en el arranque del presente siglo, específicamente entre 2003 y 2015, tomando como ejes analíticos variables clave como lugar de nacimiento, área de formación académica, nivel o grado alcanzado, estatus migratorio, certificación laboral, tasas de ocupación e ingresos. La fuente de información empleada es la Encuesta Nacional de Graduados Universitarios (NSCG, por sus siglas en inglés), levantada por la Fundación Nacional para la Ciencia (National Science Foundation). Se consideraron tres años de esta encuesta (2003, 2010 y 2015), no solo porque abarcan un periodo de tiempo razonable para observar cambios sociodemográficos y laborales de esta población, sino también porque los archivos públicos de los tres años referidos incluyen información sobre el país de nacimiento y estatus migratorio, desagregado en ciudadanos y no ciudadanos. Estos últimos se dividen, a su vez, en residentes permanentes, que son aquellos que cuentan con permiso -como la llamada green card-que les otorga la residencia estadounidense, y los temporales, es decir, aquellos que cuentan con algún tipo de visa de trabajo. La población considerada en la encuesta es la de graduados universitarios residentes en Estados Unidos, con al menos una licenciatura y hasta 75 años de edad.

La estrategia metodológica empleada consistió en comparar las características sociodemográficas y laborales de esta población tomando en cuenta cinco grupos por país o región de nacimiento: 1) nativos de Estados Unidos, 2) Europa y Canadá, 3) Asia, 4) México y 5) Latinoamérica y el Caribe, así como su situación migratoria en ese país. El trabajo destaca principalmente el caso de los migrantes mexicanos y, dependiendo de la relevancia de la información y de los resultados, se hacen comparaciones con otros grupos de inmigrantes y con la población de graduados universitarios nacidos en Estados Unidos. Cabe mencionar que, debido al tamaño de la muestra de algunas variables de la encuesta consideradas en el estudio, y con el fin asegurar la validez estadística del análisis realizado, así como por la estrategia analítica adoptada, en algunos temas o subtemas desarrollados a lo largo del texto no se presentan comparaciones considerando los tres años de la NSCG.

El trabajo consta de dos grandes apartados. En el primero se presenta una descripción general del volumen y las características educativas y migratorias de la población con estudios universitarios en Estados Unidos, comparando los grupos por su lugar de nacimiento y analizando los cambios ocurridos entre 2003 y 2015. La segunda parte se centra en el análisis de la inserción laboral de los cinco grupos poblacionales anteriormente mencionados, destacando el caso de los migrantes 
mexicanos y resaltando algunos de los rasgos de su participación económica y laboral, tales como su ocupación principal y nivel de ingreso. A diferencia del primer apartado, que pone el énfasis en los cambios ocurridos en el periodo 2003-2015, el análisis de las condiciones de inserción laboral se centra en 2015.

\section{Población de profesionistas mexicanos en Estados Unidos}

La emigración de profesionales mexicanos a Estados Unidos ha crecido de manera significativa en las últimas décadas (Lozano \& Gandini, 2010) debido a la cada vez mayor participación de hombres y mujeres con alto nivel educativo y formados en distintas áreas de la ciencia, así como estudiantes internacionales. Los datos recopilados por la NSCG indican que el número de profesionales mexicanos residentes en Estados Unidos pasó de poco más de 190 mil en 2003 a 444 mil en 2015. Según dicha fuente, la población de migrantes calificados mexicanos está compuesta principalmente por personas con estudios de licenciatura, quienes aumentaron de 128 mil a 330 mil entre 2003 y 2015. En cambio, los posgraduados, es decir quienes cuentan con una maestría, doctorado y grado profesional, aunque también acrecentaron su cuantía de 61 mil a 113 mil personas, en términos relativos registraron un ligero descenso en el periodo analizado. Dicho perfil educativo contrasta fuertemente con el ostentado por los profesionistas nativos y otros migrantes, entre los cuales la proporción de aquellos que cuentan con estudios de posgrado, especialmente entre los europeos y asiáticos, es por mucho superior a la de los mexicanos (véase cuadro 1).

Esta población está compuesta por profesionistas mexicanos que cursaron sus estudios tanto en México como en Estados Unidos, y en su crecimiento ha influido una diversidad de factores demográficos, económicos, políticos y sociales, entre los que se pueden mencionar: la mejor calidad del sistema educativo estadounidense frente a la del mexicano, la brecha del desarrollo científico y tecnológico, las diferencias salariales y oportunidades profesionales, y la cercanía geográfica entre ambos países (Ávila, 2015). Así como las políticas migratorias implementadas por el gobierno norteamericano para atraer, retener y reclutar estudiantes y profesionistas altamente calificados (Cruz Piñeiro \& Ruiz Ochoa, 2010). Un ejemplo de dicha política fue la Acción Ejecutiva sobre Inmigración propuesta por Barack Obama en 2014, entonces presidente de Estados Unidos, la cual contemplaba, entre otras medidas, proporcionar autorización de estadía y empleo a trabajadores altamente calificados que se encontraban en espera de la concesión de residencia legal, así como capacitar y ampliar las oportunidades laborales para los profesionales formados en áreas de las ciencias, tecnología, ingenierías y matemáticas (стім) que se hayan graduado en universidades estadounidenses (Lozano \& Ramírez, 2015a). En 


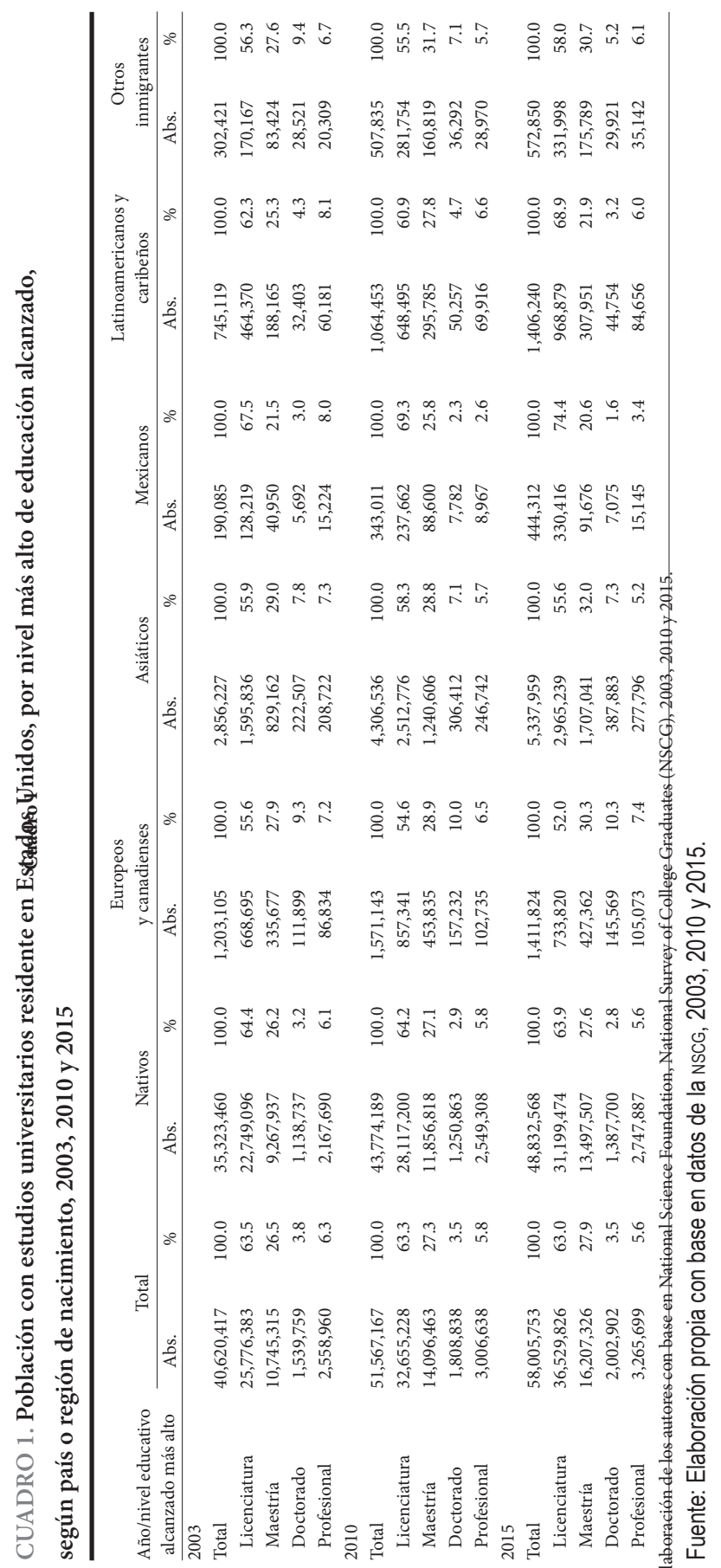


2013 estaban vigentes 911 mil visas de trabajadores especializados, bajo el esquema de visas H-1B, L-1 y F-1 (Costa \& Rosenbaum, 2017).

Los datos anteriores indicarían que la migración calificada mexicana a Estados Unidos se presenta mayoritariamente entre personas con estudios de licenciatura, mientras que las migraciones de otras regiones del mundo involucran una alta proporción de profesionales con estudios de posgrado, lo cual indicaría que la migración mexicana es de menor calificación. Sin embargo, no es poco común que algunos mexicanos continúen o retomen sus estudios en ese país, ya que para muchos jóvenes estudiar en el extranjero es solo el primer paso para desarrollar una trayectoria educativa, residencial y laboral más larga en el país receptor, sobre todo entre las mujeres, población que representa una proporción muy significativa de los flujos de estudiantes internacionales (Pellegrino \& Martínez, 2001). Ello debido a que, en comparación con los hombres, las mujeres enfrentan mayores dificultades para integrarse al sistema educativo y el mercado laboral de sus países de origen (Lozano, Gandini \& Ramírez, 2015; Lozano \& Ramírez, 2015b), así como para emigrar a otro país. De ahí que muchas mujeres decidan establecerse o permanecer por más tiempo en los países de destino (Woo, 2001). Al respecto, la NSCG muestra, en términos generales, un crecimiento relativo de la población calificada femenina. No obstante, cabe destacar que tal aumento fue mayor entre las mexicanas que entre las nativas y otras migrantes, las cuales pasaron de representar $48.5 \%$ en 2003 a $55.9 \%$ en 2015. Estos datos corroboran, además, la tendencia de una creciente presencia de mujeres en la migración calificada mexicana, lo cual se ha documentado en otras investigaciones (Docquier, Lowell \& Marfouk, 2009; Gandini \& Lozano, 2012; Ramírez \& Gandini, 2016).

\section{Perfil educativo y estatus migratorio de los profesionistas mexicanos residentes en Estados Unidos}

Estados Unidos es el país con mayor poder de atracción de población migrante calificada a nivel mundial, debido a su liderazgo internacional en el desarrollo de actividades científicas y tecnológicas, una agresiva política migratoria enfocada en reclutar recursos humanos altamente calificados, un mercado laboral que ofrece el acceso a empleos de alta calificación, así como a sus políticas de financiamiento a la investigación. Ello se manifiesta al observar la alta proporción de migrantes que obtienen sus títulos universitarios y de posgrado en áreas vinculadas con las ciencias, la tecnología, las ingenierías y las matemáticas (стім) (Hanson \& Slaughter, 2013; Peri, 2017). De acuerdo con la información presentada en el cuadro 3, tal situación es especialmente notoria en el caso de los profesionistas asiáticos y mexicanos con educación superior. Entre los primeros, que incluyen a dos grupos de población 
CUADRO 2. Población con estudios universitarios residente en Estados Unidos, por sexo según país o región de nacimiento, 2003, 2010 y 2015

\begin{tabular}{|c|c|c|c|c|c|c|c|}
\hline Año/sexo & Total & Nativos & $\begin{array}{l}\text { Europeos y } \\
\text { canadienses }\end{array}$ & Asiáticos & Mexicanos & $\begin{array}{c}\text { Latinoamericanos y } \\
\text { caribeños }\end{array}$ & $\begin{array}{c}\text { Otros } \\
\text { inmigrantes }\end{array}$ \\
\hline 2003 & 100.0 & 100.0 & 100.0 & 100.0 & 100.0 & 100.0 & 100.0 \\
\hline Hombres & 50.6 & 50.3 & 53.7 & 52.6 & 51.5 & 45.6 & 63.4 \\
\hline Mujeres & 49.4 & 49.7 & 46.3 & 47.4 & 48.5 & 54.4 & 36.6 \\
\hline 2010 & 100.0 & 100.0 & 100.0 & 100.0 & 100.0 & 100.0 & 100.0 \\
\hline Hombres & 48.0 & 47.4 & 51.5 & 51.2 & 55.3 & 46.4 & 62.0 \\
\hline Mujeres & 52.0 & 52.6 & 48.5 & 48.8 & 44.7 & 53.6 & 38.0 \\
\hline 2015 & 100.0 & 100.0 & 100.0 & 100.0 & 100.0 & 100.0 & 100.0 \\
\hline Hombres & 47.4 & 47.0 & 50.7 & 49.6 & 44.1 & 45.0 & 59.6 \\
\hline Mujeres & 52.6 & 53.0 & 49.3 & 50.4 & 55.9 & 55.0 & 40.4 \\
\hline
\end{tabular}

Fuente: Elaboración propia con base en datos de NSCG, 2003, 2010 y 2015.

de un considerable volumen -los de China e India-, la población de graduados en áreas de la computación, matemáticas, ingenierías y ciencias naturales aumentó de $36.5 \%$ en 2003 a $40.9 \%$ en 2015 , en tanto que en los segundos dicho porcentaje pasó de $20.6 \%$ a $24.7 \%$ entre 2003 y 2015.

Si bien estos porcentajes también son altos entre los profesionales procedentes de Europa y Canadá, su incremento fue menor durante el periodo observado, al igual que entre los originarios de otros países de América Latina y el Caribe. Ambos grupos poblacionales registraron un mayor porcentaje de migrantes formados en otras áreas del conocimiento, entre las que se encuentran educación, leyes, negocios y administración pública, por mencionar algunas. Tal situación es observada también en los nativos estadounidenses, entre los cuales alrededor de siete de cada diez estudiaron alguna de estas profesiones, tendencia que se ha mantenido prácticamente estable. Además, es importante resaltar que entre los nativos la matrícula de egresados de licenciaturas o posgrados en computación, matemáticas, ingenierías y ciencias naturales, así como en otras profesiones de las ciencias sociales, se ha estancado; es decir, no ha cambiado a lo largo de los últimos años, lo cual justificaría el reclutamiento y la retención de migrantes graduados en áreas Стім.

En efecto, los datos del cuadro 3 dan cuenta de un incremento en el número de profesionistas extranjeros graduados en áreas vinculadas con el desarrollo de actividades científicas y tecnológicas, quienes se han asentado o establecido al menos temporalmente en Estados Unidos, debido a que posiblemente con los conocimientos, destrezas y habilidades adquiridos durante su formación profesional han logrado colocarse en empresas de alta tecnología, así como en centros de investigación e instituciones educativas, o bien porque han decidido permanecer en ese país con el propósito de desarrollar una trayectoria laboral en el área del conocimiento en la 
que se formaron. Tal proyecto sería, en algunos casos, más difícil de realizar en sus países de origen debido al limitado desarrollo científico y tecnológico, la carencia de infraestructura adecuada y la falta de oportunidades laborales que enfrentan cuando retornan. Tal como se ha señalado en el caso de los migrantes mexicanos calificados (Tuirán \& Ávila, 2013), quienes presentan un bajo índice de retorno a México, que no se corresponde con la magnitud de la migración calificada mexicana, especialmente entre aquellos migrantes que cuentan con estudios de posgrado (Ramírez \& Lozano, 2015).

Estas desventajas prevalecientes en algunas naciones en desarrollo expulsoras de población migrante calificada son aprovechadas por los países receptores para reclutar y retener a los mejores y más brillantes profesionistas, sobre todo aquellos graduados en áreas стім, como ya se ha anunciado. En Estados Unidos, como en otros países industrializados, existe un amplio consenso en el sentido de que los especialistas en áreas стім son fundamentales en los procesos de innovación e incremento de la productividad, dado que su trabajo está ligado a la generación de nuevas ideas, nuevas tecnologías y nuevas empresas e industrias (Hanson \& Slaughter, 2013; Lozano \& Ramírez, 2015a, 2015b). A lo anterior habría que sumarle el hecho de que en algunas de esas naciones receptoras de mano de obra calificada su población se encuentran en un proceso de envejecimiento, por lo que la migración es considerada como un mecanismo para satisfacer sus requerimientos de mano de obra tanto calificada como no calificada (Pellegrino \& Martínez, 2001), a fin de mantener su competitividad y liderazgo internacional. Sin embargo, estos no son los únicos factores que estimulan y han sostenido la migración calificada en el mundo contemporáneo, sino también el creciente protagonismo de las empresas multinacionales, las cuales han desempeñado un papel importante en dicho proceso, ya que en sus afanes competitivos suelen reclutar trabajadores y estudiantes destacados en áreas vinculadas con los negocios, la tecnología informática y algunos servicios afines. Estas cuestiones ponen de relieve la importancia estratégica que la migración calificada tiene para los países de acogida, la economía mundial y para los propios migrantes (Pellegrino \& Martínez, 2001).

Una forma de profundizar en el análisis de las estrategias que el gobierno de Estados Unidos ha desplegado para garantizar la retención y el reclutamiento de migrantes calificados es a través del estatus migratorio que poseen los profesionistas que han emigrado o se han quedado en ese país después de haber concluido sus estudios de licenciatura o posgrado. A través de dicho indicador no solo es posible identificar su situación migratoria sino también conocer su proceso de integración a la sociedad estadounidense. $\mathrm{Al}$ respecto, los datos del cuadro 4 parecen sustentar las argumentaciones anteriormente señaladas, en el sentido de que muestran que más de la mitad de los profesionistas migrantes encuestados en los tres años de levantamiento de la NSCG considerados en este análisis se ha naturalizado, es decir, 
CUADRO 3. Población con estudios universitarios residente en Estados Unidos, por área de formación profesional según país o región de nacimiento, 2003, 2010 y 2015 (Porcentajes)

\begin{tabular}{|c|c|c|c|c|c|c|c|}
\hline Año/área de formación profesional & Total & Nativos & $\begin{array}{l}\text { Europeos y } \\
\text { canadienses }\end{array}$ & Asiáticos & Mexicanos & $\begin{array}{l}\text { Latinoamericanos y } \\
\text { caribeños }\end{array}$ & $\begin{array}{c}\text { Otros } \\
\text { inmigrantes }\end{array}$ \\
\hline \multicolumn{8}{|l|}{2003} \\
\hline Total & 100.0 & 100.0 & 100.0 & 100.0 & 100.0 & 100.0 & 100.0 \\
\hline $\begin{array}{l}\text { Computación, matemáticas, ingenierías y } \\
\text { ciencias naturales }\end{array}$ & 16.8 & 14.8 & 25.2 & 36.5 & 20.6 & 19.3 & 29.5 \\
\hline Ciencias sociales y relacionadas & 10.5 & 10.6 & 12.3 & 7.8 & 9.8 & 10.6 & 8.4 \\
\hline Otras áreas & 72.7 & 74.6 & 62.6 & 55.7 & 69.6 & 70.1 & 62.0 \\
\hline \multicolumn{8}{|l|}{2010} \\
\hline Total & 100.0 & 100.0 & 100.0 & 100.0 & 100.0 & 100.0 & 100.0 \\
\hline $\begin{array}{l}\text { Computación, matemáticas, ingenierías y } \\
\text { ciencias naturales }\end{array}$ & 16.9 & 14.2 & 26.9 & 38.2 & 20.3 & 20.9 & 24.2 \\
\hline Ciencias sociales y relacionadas & 11.2 & 11.4 & 15.2 & 8.0 & 13.9 & 10.1 & 10.0 \\
\hline Otras áreas & 71.9 & 74.4 & 58.0 & 53.8 & 65.8 & 69.1 & 65.8 \\
\hline \multicolumn{8}{|l|}{2015} \\
\hline Total & 100.0 & 100.0 & 100.0 & 100.0 & 100.0 & 100.0 & 100.0 \\
\hline $\begin{array}{l}\text { Computación, matemáticas, ingenierías y } \\
\text { ciencias naturales }\end{array}$ & 18.1 & 15.2 & 28.1 & 40.9 & 24.7 & 19.3 & 26.7 \\
\hline Ciencias sociales y relacionadas & 11.7 & 12.0 & 10.9 & 9.5 & 14.1 & 10.3 & 11.2 \\
\hline Otras áreas & 70.2 & 72.9 & 61.0 & 49.6 & 61.3 & 70.4 & 62.2 \\
\hline
\end{tabular}

Fuente: Elaboración propia con base en NSCG, 2003, 2010 y 2015.

han obtenido la ciudadanía estadounidense. Este resultado podría ser indicativo de una mejor integración socioeconómica de estos migrantes calificados, ya que la adquisición de la ciudadanía les permite ejercer sus derechos como ciudadanos y tener acceso a distintos beneficios y prestaciones sociales, como derecho al trabajo, acceso a becas estudiantiles, ocupar cargos de representación popular y la reunificación familiar, por mencionar algunos de ellos. Esto, indudablemente, favorece el desarrollo de trayectorias educativas, laborales y profesionales mucho más exitosas.

Asimismo, un porcentaje importante de los migrantes que no son ciudadanos estadounidenses cuenta con la residencia permanente, $\mathrm{y}$ un porcentaje menor con la residencia temporal, la cual se obtiene a través de las visas de trabajo $\mathrm{H}-1 \mathrm{~B}, \mathrm{~L}-1 \mathrm{~A}$, L-1B, etc., y visas para estudio o entrenamiento J-1, F-1, H-3. Las visas H-1B (antes de 1991, simplemente visas H-1) son para trabajadores en ocupaciones especializadas, $\mathrm{y}$ sus portadores deben poseer un conocimiento especializado y al menos una licenciatura o equivalente. Las visas L-1A y L-1B son de intercambio de personal entre empresas, por lo que el titular debe haber trabajado para la empresa al menos durante un año y tener título de licenciatura o equivalente. Las visas F-1, J-1, H-3 son para profesores, estudiantes, posdoctorantes y pasantes (Hunt, 2011).

En este conjunto poblacional destacan los profesionistas mexicanos, entre los cuales el porcentaje de residentes temporales aumentó de $6.7 \%$ a $18.8 \%$ entre 2003 y 2015, aunque con una ligera disminución entre 2010 y 2015, posiblemente a consecuencia de la crisis de 2010. Dicho crecimiento también se registró entre la po- 
blación de asiáticos, quienes pasaron de $8.9 \%$ a $17.4 \%$. Estas cifras, a su vez, nos permiten suponer la existencia de un mayor reclutamiento de migrantes calificados mexicanos y asiáticos en los últimos años, en comparación con nativos de otros países y regiones del mundo. Por ejemplo, entre el resto de los nativos de América Latina y el Caribe la proporción de profesionales con permiso de residencia temporal únicamente creció de $5.9 \%$ a $7.2 \%$. En este caso, como entre los europeos y canadienses, el elevado porcentaje de migrantes naturalizados y de residentes permanentes apoyaría la hipótesis enunciada líneas arriba, ya que la adquisición de ambos estatus migratorios son procesos que pueden llevar varios años (véase cuadro 4). De hecho, del total de los profesionistas migrantes que contaban con visa de trabajo temporal en 2003, 61.8\% eran asiáticos, cifra que aumentó a $73.7 \%$ en 2015, en tanto que los mexicanos con visa de trabajo temporal pasaron de representar 3.1\% a 5.5\% del total. Ambos grupos de migrantes calificados fueron, además, los únicos que experimentaron un crecimiento positivo en el periodo analizado (véase gráfica 1).

Ahora bien, ¿en qué áreas del conocimiento se formaron los profesionistas inmigrantes radicados en Estados Unidos? Más específicamente, ¿existen diferencias entre grupos según condición migratoria? Como ya se anotó líneas arriba, los datos recopilados por la NSCG muestran que, a diferencia de los profesionistas migrantes, los nativos presentan una baja representación en el grupo de graduados en licenciaturas y posgrados en computación, matemáticas, ingenierías y ciencias naturales, es decir, en áreas no стім; por el contrario, están sobrerrepresentados en el grupo de

GRÁFICA 1. Distribución porcentual de la población migrante con estudios universitarios que cuenta con visa de trabajo temporal, residente en Estados Unidos, según país o región de nacimiento, 2003 y 2015

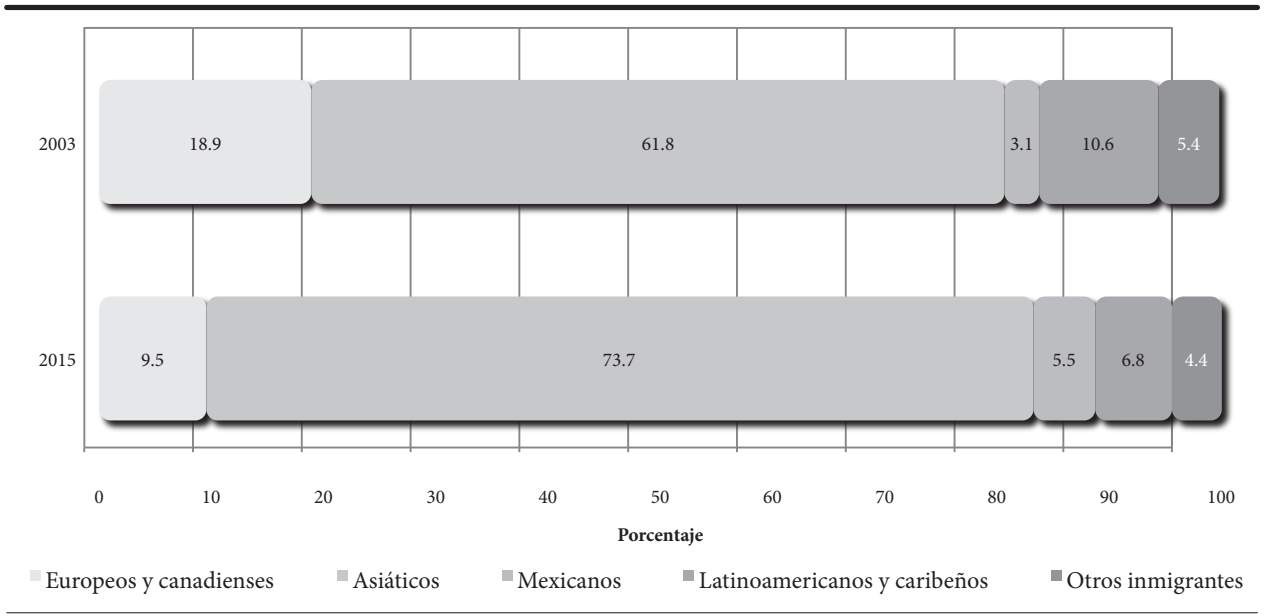

Fuente: Elaboración propia con base en datos de NSCG, 2003 y 2015. 


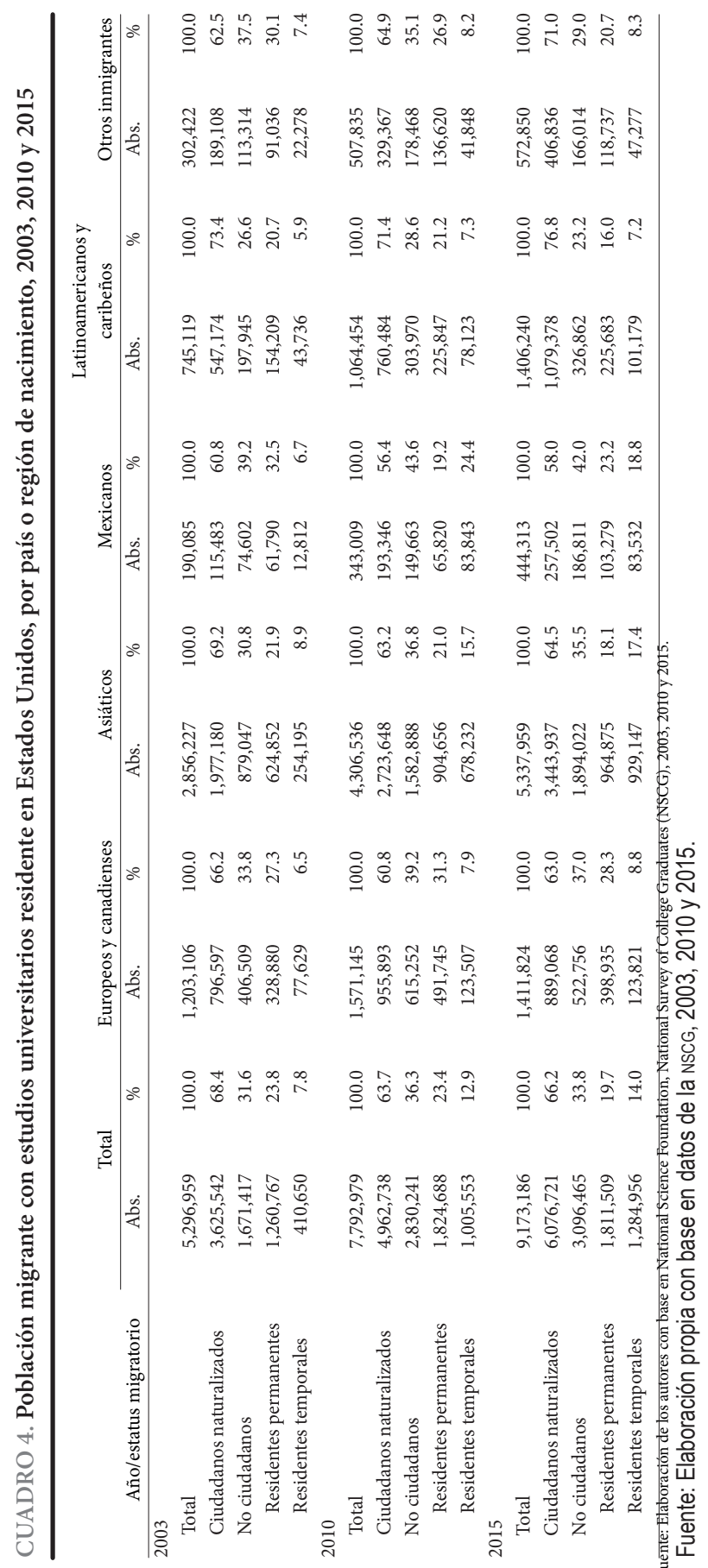


egresados de otras áreas del conocimiento. ${ }^{1}$ Este mismo patrón de concentración se presenta en aquellos migrantes que han adquirido la ciudadanía estadounidense, con excepción de los asiáticos, entre los cuales la proporción de profesionales especialistas en áreas стім también es importante (véase cuadro 5). Contrariamente, entre los migrantes que no cuentan con la ciudadanía estadounidense es notable el predominio de los graduados en computación, matemáticas, ingenierías y ciencias naturales, lo cual corroboraría la existencia de una selectividad positiva por este tipo de profesionistas migrantes. De hecho, su cuantía es todavía mayor entre los residentes temporales que entre los permanentes, situación que se presenta en todos los grupos de migrantes calificados, pero resulta especialmente notoria en el caso de los asiáticos y mexicanos. Entre los asiáticos, casi $40 \%$ de los residentes permanentes y $62.4 \%$ de los temporales estudió computación, matemáticas, ingenierías o ciencias naturales en alguna universidad estadounidense, en tanto que entre los mexicanos residentes permanentes y temporales que se formaron en esas áreas del conocimiento fueron de $16.9 \%$ y 53.5\%, respectivamente (véase cuadro 5).

La supremacía de los profesionales asiáticos en áreas стім explica por qué Asia sigue siendo el principal continente de origen de los científicos e ingenieros inmigrantes en Estados Unidos. De acuerdo con un reporte realizado por Lan, Hale y Rivers (2015) para el Centro Nacional de Ciencias y Estadísticas de Ingeniería (NCSES, por sus siglas en inglés), en 2013 residían en Estados Unidos 950 mil científicos e ingenieros de la India (naturalizados, ciudadanos, residentes permanentes y temporales con visa). Según dicho documento, entre 2003 y 2013 los científicos e ingenieros filipinos aumentaron en 53\% y el número de los nativos de China, que incluye a los nacidos en Hong Kong y Macao, en 34\%. Asimismo, según datos de la American Community Survey (ACs) de 2013, los ingenieros mexicanos constituían alrededor del $18 \%$ del stock de migrantes calificados nacidos en México y residentes en aquel país. Sin embargo, a diferencia de los países asiáticos, su volumen es mucho menor. Además, como señalan Cruz-Piñeiro y Ruiz Ochoa (2010), es evidente que México todavía debe recorrer un largo camino para posicionar a sus profesionistas en los mercados laborales internacionales no solo debido al rezago educativo que padece, sino también a los pocos acuerdos de reconocimiento mutuo (ARM) que ha logrado con otros países. ${ }^{2}$ Estas tendencias, indudablemente, son resultado de la política migratoria estadounidense de reclutar a los mejores y más brillantes

Las áreas de formación se agruparon en solo dos conjuntos debido a que el tamaño de la muestra de la encuesta desagregado por estatus migratorio no era suficientemente grande para hacer comparaciones estadísticamente confiables entre los grupos analizados.

2 A través de los ARM, cada país involucrado otorga y tiene la autoridad para evaluar y certificar títulos o certificados educativos de acuerdo con los requisitos legislativos de su contraparte, en su propio territorio. 


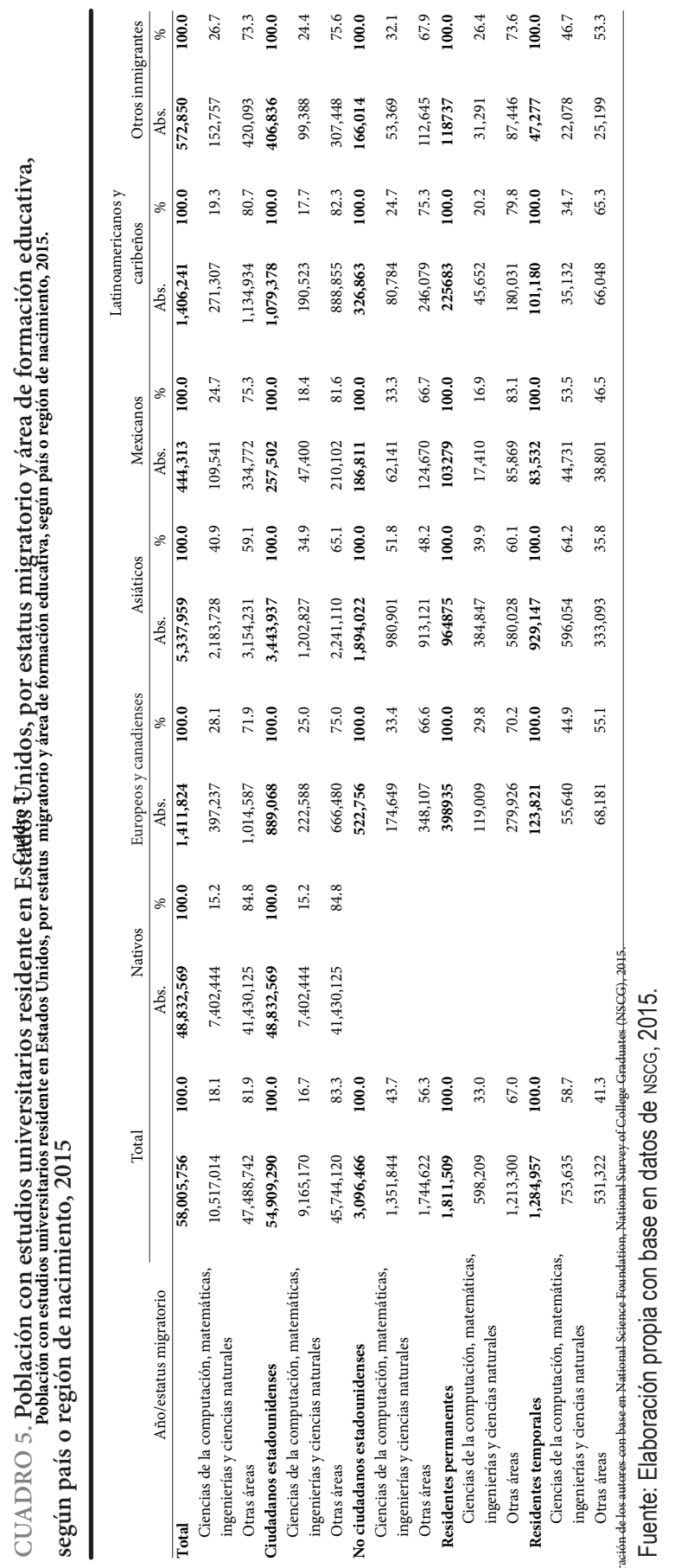


profesionistas extranjeros, a la que algunos autores denominan quality-selectivity immigration policies (Antecol, Cobb-Clark \& Trejo, 2003).

\section{Inserción de los profesionistas mexicanos en el mercado laboral estadounidense}

En apartados anteriores se presentó una descripción general sobre el volumen y las características educativas y migratorias de los profesionistas mexicanos residentes en Estados Unidos. Esta segunda parte se centra en analizar su inserción ocupacional en el mercado laboral de Estados Unidos. Sobre este punto, la evidencia empírica con la que se cuenta muestra que los mexicanos enfrentan diversas barreras para integrarse al mercado de trabajo estadounidense y que, en general, lo hacen en condiciones más desfavorables que los nativos y que otros trabajadores migrantes con el mismo nivel educativo, e incluso controlando por área de especialización (Gandini \& Lozano, 2012; Lozano, Gandini \& Ramírez, 2015; Lozano \& Ramírez, 2015; Amaro, 2016; Calva \& Alarcón, 2015; Ramírez \& Gandini, 2016; Becerril, Canales, Cruz \& Ocampo, 2016).

En los estudios citados anteriormente se coincide en que los problemas relacionados con el dominio del idioma inglés, la acreditación y revalidación de títulos educativos, la condición migratoria y el tiempo de estancia en Estados Unidos, así como el lugar de obtención del título profesional, son algunos de los factores que inciden negativamente en su inserción laboral. Por ejemplo, Lozano, Gandini y Ramírez (2015) encuentran que los migrantes mexicanos calificados formados en áreas стім que no contaban con la ciudadanía estadounidense, no dominaban bien el idioma inglés y habían obtenido su título profesional en México, tenían menos posibilidades de insertarse en una ocupación altamente calificada en Estados Unidos; es decir, en un trabajo que demande conocimientos, habilidades y destrezas adquiridas durante su formación educativa. Los autores concluyen que buena parte de estos talentos mexicanos se encontraban afectados por un problema de subutilización de sus capacidades, situación que no solo afecta a los mexicanos en ese país, sino que es un fenómeno que también enfrentan otros migrantes calificados en otros países de acogida (Green, Kler \& Leeves, 2007; Bauder, 2003; Salami \& Nelson, 2014; Fernández \& Ortega, 2008; Mattoo, Neagu \& Özden, 2008; Lindley, 2009) e incluso en sus naciones de origen (Hernández, Solís \& Stefanovich, 2013).

La acreditación y revalidación de títulos es quizás uno de los mayores obstáculos que enfrentan muchos profesionales migrantes para integrarse a las sociedades de llegada; sin embargo, en el caso de los migrantes calificados mexicanos radicados en Estados Unidos dicha problemática es un tema poco explorado hasta la fecha, además poco se ha abordado desde una perspectiva cuantitativa o macrosocial. Bauder (2003) denomina tal problemática de-skilling debido a la falta de re- 
conocimiento de títulos y experiencia laboral que poseen los migrantes calificados por parte de las instituciones profesionales y empleadores en los países receptores. Según este autor, se trata de una discriminación institucionalizada ya que a pesar de contar con cualidades similares de educación y formación que la población nativa, la falta de acreditación y revalidación de títulos universitarios o experiencia laboral de los profesionales migrantes los sitúa en una posición de desigualdad laboral y salarial frente a la población nativa, lo cual genera también desigualdades en el acceso laboral y salarial entre los grupos de profesionales según origen nacional.

\section{Participación económica y laboral}

Dos indicadores básicos para evaluar en forma comparada el desempeño de los migrantes calificados en el mercado de trabajo estadounidense son la tasa de participación económica y la de ocupación. La primera permite conocer cuántos de los profesionistas mexicanos formaban parte de la población económicamente activa de ese país y cuántos se encontraban trabajando durante el periodo de referencia de la encuesta, levantada en la primera semana de febrero de 2015. Al respecto, los datos del cuadro 6 muestran que tanto la población mexicana como la nativa y la de otros migrantes calificados presentan altas tasas de participación económica, incluso las registradas por los procedentes de países latinoamericanos y caribeños y de otras naciones del mundo son superiores al promedio nacional. Tales tasas de participación económica se corresponden con altas tasas de ocupación, las cuales se ubican alrededor del $80 \%$ en todos los grupos. En el caso de los mexicanos, dicha tasa indica que casi 8 de cada 10 personas se encontraban ocupadas o estaban trabajando en la primera semana de febrero de 2015.

No obstante, al analizar dichos indicadores laborales según el estatus migratorio de los profesionistas mexicanos se observan diferencias importantes. Los que cuentan con la ciudanía estadounidense, es decir, los que ya se han naturalizado, presentan tasas de participación económica y de ocupación superiores a las de aquellos que no cuentan con dicho estatus migratorio: $92.1 \%$ y $87.6 \%$ versus $71.1 \%$ y $66.3 \%$, respectivamente. Lo más sorprendente es que tal situación no se presenta entre los demás grupos de inmigrantes, con excepción de los procedentes de otros países de América Latina y el Caribe, entre los cuales la tasa de participación económica registra una disminución, no así la tasa de ocupación. El problema de la desocupación laboral de los mexicanos no ciudadanos estadounidenses se recrudece cuando se comparan las tasas de participación económica y de ocupación según condición de residencia en Estados Unidos, las cuales resultan particularmente bajas entre los residentes temporales, pues solo alrededor de la mitad de ellos eran económicamente activos y estaban ocupados al levantarse la encuesta. Tal problemática también 


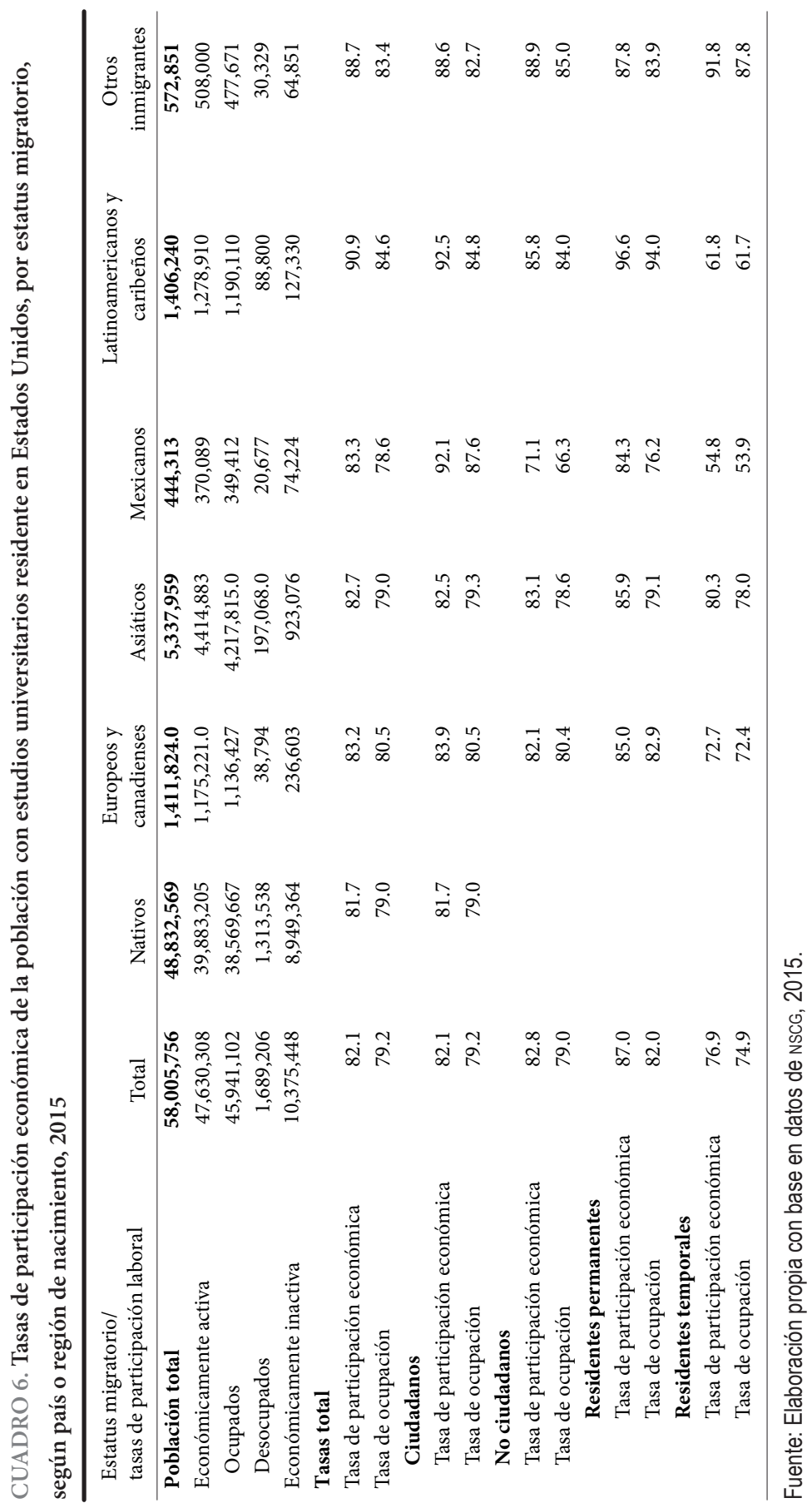


se presenta entre los latinoamericanos y caribeños que cuentan con dicho estatus migratorio, aunque no al mismo nivel que en los profesionales mexicanos. Ambos indicadores dan cuenta de que los migrantes mexicanos calificados y el resto de los latinoamericanos residentes temporales, que en su mayoría cuenta con visas de trabajo, como se anotó anteriormente, enfrentan mayores obstáculos para integrarse al mercado laboral de profesionistas en Estados Unidos. Este hallazgo corrobora lo reportado en algunas investigaciones cualitativas realizadas con grupos específicos de profesionistas mexicanos migrantes (Calva Sánchez \& Alarcón, 2015).

Sin embargo, la pregunta que aún falta responder es ¿qué factores explican los menores niveles de participación laboral de los migrantes calificados residentes temporales? En otros trabajos que hemos realizado con otras fuentes de información y técnicas metodológicas encontramos que los profesionales mexicanos que no contaban con la ciudadanía estadounidense y habían obtenido su título universitario en México eran menos propensos a insertarse en una ocupación acorde a su escolaridad (véase Lozano, Gandini \& Ramírez, 2015; Lozano \& Ramírez, 2016), por lo que podría suponerse que dicha problemática esté relacionada con la falta de certificación profesional o de una licencia para trabajar en ese país. Con la finalidad de explorar tal hipótesis, hemos estimado la población profesionista nativa y emigrante que cuenta con una certificación o licencia para realizar un trabajo específico (por ejemplo, maestros, médicos y enfermeras, ingenieros, etc.), según condición migratoria. Esta certificación o licencia es otorgada por autoridades educativas y laborales de Estados Unidos (Finamore \& Foley, 2017).

Tales resultados se presentan en el cuadro 7, y de ellos se desprende que, en términos generales, el porcentaje de profesionales migrantes con alguna certificación o licencia de trabajo es menor que en los nativos. Entre los mexicanos, alrededor de 3 de cada 10 cuentan con dicho documento, proporción muy similar a la que ostentan otros migrantes. No obstante, si se considera únicamente a la población económicamente activa, el porcentaje se incrementa ligeramente en todos los grupos de migrantes -con excepción de los procedentes de otros países de América Latina y el Caribe, cuyas proporciones se mantienen prácticamente iguales-, lo cual revela la importancia de contar con dicha documentación para incursionar en el mercado laboral estadounidense, sobre todo para ejercer determinadas ocupaciones. Empero, aun así persisten diferencias según situación migratoria de los profesionales migrantes. En todos los casos, con excepción de los mexicanos, el porcentaje de profesionales certificados o con licencia de trabajo es mayor en aquellos que cuentan con la ciudadanía estadounidense, por lo que se podría suponer que contar dicho estatus migratorio también facilita el acceso a la certificación y la obtención de licencias de trabajo.

Lo anterior parece corroborarse al analizar los porcentajes de población sin ciudadanía estadounidense según tipo de residencia en Estados Unidos, pues en 
el caso de los mexicanos una alta proporción de los que cuentan con la residencia permanente tienen al menos una certificación o licencia. En cambio, las condiciones de mayor exclusión se presentan entre sus compatriotas residentes temporales, pues únicamente $14.3 \%$ de ellos cuenta con tales requerimientos laborales. Esta situación también se presenta en todos los demás grupos de migrantes (véase cuadro 7), lo cual está fuertemente asociado con las bajas tasas de participación económica y de ocupación que ostentan los profesionistas con estatus temporal. Recordemos que una alta proporción de los mexicanos y asiáticos que se encuentran en esta situación migratoria se formaron en áreas relacionadas con la computación, matemáticas, ingenierías y ciencias naturales, la mayoría de las cuales requieren de una certificación o licencia para poder ejercerse.

\section{Ocupación principal}

El tipo de ocupación en el que se desempeñan los migrantes tiene un papel central en su proceso de integración socioeconómica, pero también da cuenta de la selectividad de la mano de obra calificada, así como de su aprovechamiento en los procesos de desarrollo científico y tecnológico en las sociedades de destino. Sobre este punto, los datos del cuadro 8 presentan el tipo de actividades realizadas por los profesionales nativos y migrantes en su ocupación principal según estatus migratorio y lugar de origen. En dicho cuadro se puede apreciar que una proporción importante de los mexicanos calificados se emplea en una ocupación vinculada a la ciencia y las ingenierías (25.7\%), porcentaje inferior al de los asiáticos, europeos y canadienses, y del grupo de otros migrantes, pero cercano al de los nativos y otros latinoamericanos y caribeños. No obstante, al comparar tales resultados según situación migratoria se observa un incremento de la participación de los migrantes mexicanos que no se han naturalizado como ciudadanos estadounidenses en ese tipo de ocupaciones, particularmente entre los residentes temporales, quienes se ubican solo por debajo de los procedentes de Asia. Tales resultados sugieren, como ya hemos señalado en líneas anteriores, la existencia de una mayor selectividad en los últimos años por la mano de obra calificada mexicana formada y vinculada laboralmente con áreas Стім.

El sector de actividad es otro elemento importante que se debe considerar en la inserción laboral de los profesionistas mexicanos en Estados Unidos. Desafortunadamente, el tamaño de la muestra de la encuesta no permite hacer comparaciones entre los sectores económicos según los distintos tipos de estatus migratorio que hemos venido manejando, debido a la mayor concentración de los trabajadores mexicanos en ciertos sectores y su poca representación estadística en otros. Sin embargo, dichos datos permiten destacar algunas particularidades en términos ge- 


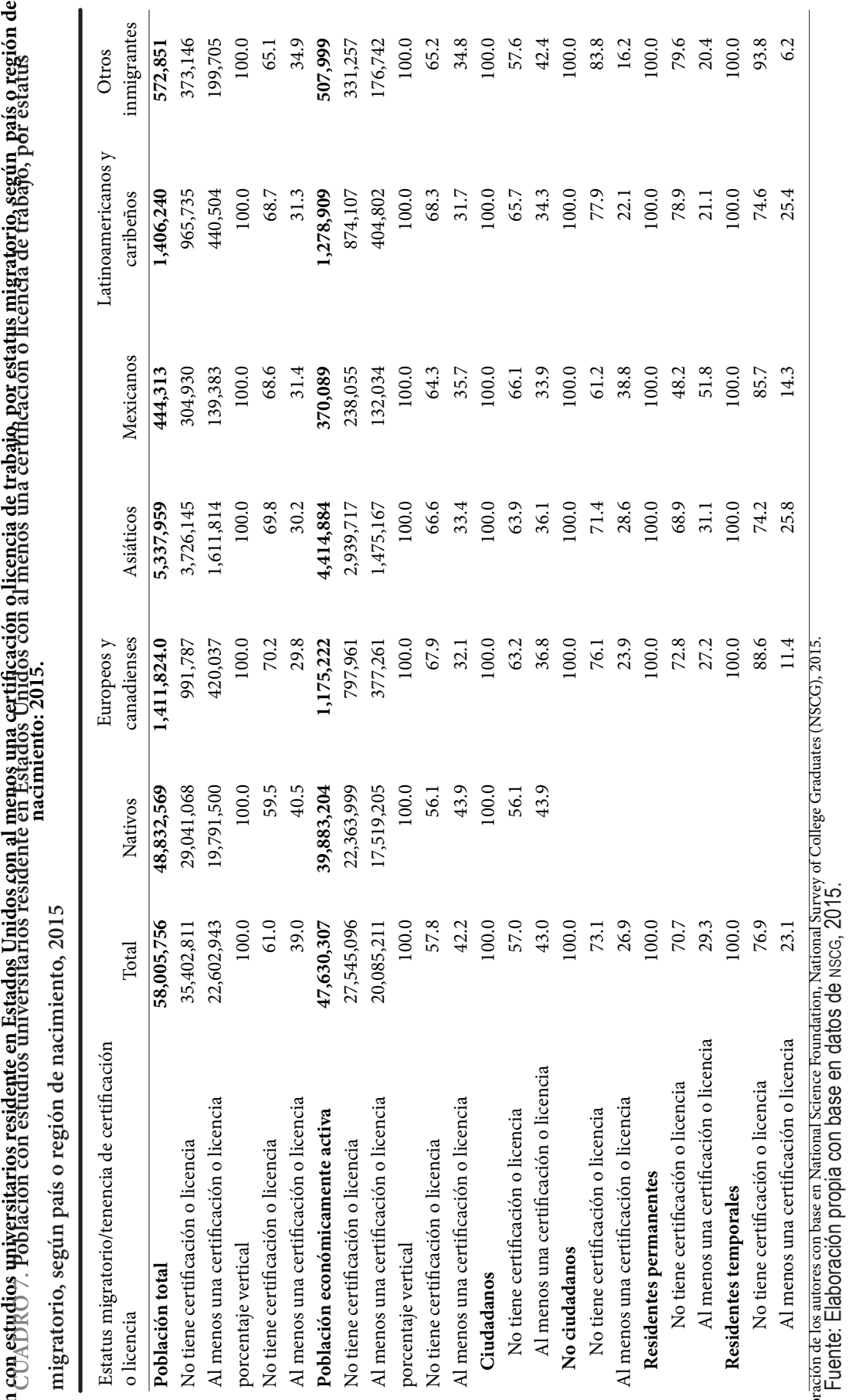


nerales, tales como la alta proporción de profesionistas mexicanos que se emplean como trabajadores por cuenta propia, situación que si bien también se presenta entre los nativos y otros migrantes, es por mucho mayor entre los mexicanos. Sobre este punto, Hunt (2011) señala que los inmigrantes con conocimientos técnicos de maestría y doctorado son más propensos que los nativos a crear empresas con más de diez trabajadores, lo cual sugiere que la creación de nuevas empresas o microempresas constituye un nicho laboral para estos profesionistas migrantes.

De hecho, los datos muestran una menor representación de los mexicanos en el sector privado, ya sea para una compañía u organización, privada o no (excepto de caridad), en comparación con otros migrantes calificados, sobre todo respecto a los asiáticos, europeos y canadienses. Es importante destacar también la significativa participación de los mexicanos y otros latinoamericanos y caribeños en el sector gobierno (véase gráfica 2), quienes se emplean en trabajos vinculados con la enseñanza y formación profesional en escuelas y universidades, es decir, en la formación de recursos humanos.

GRÁFICA 2. Población con estudios universitarios residente en Estados Unidos, por condición migratoria y sector de ocupación principal, según país o región de nacimiento, 2015

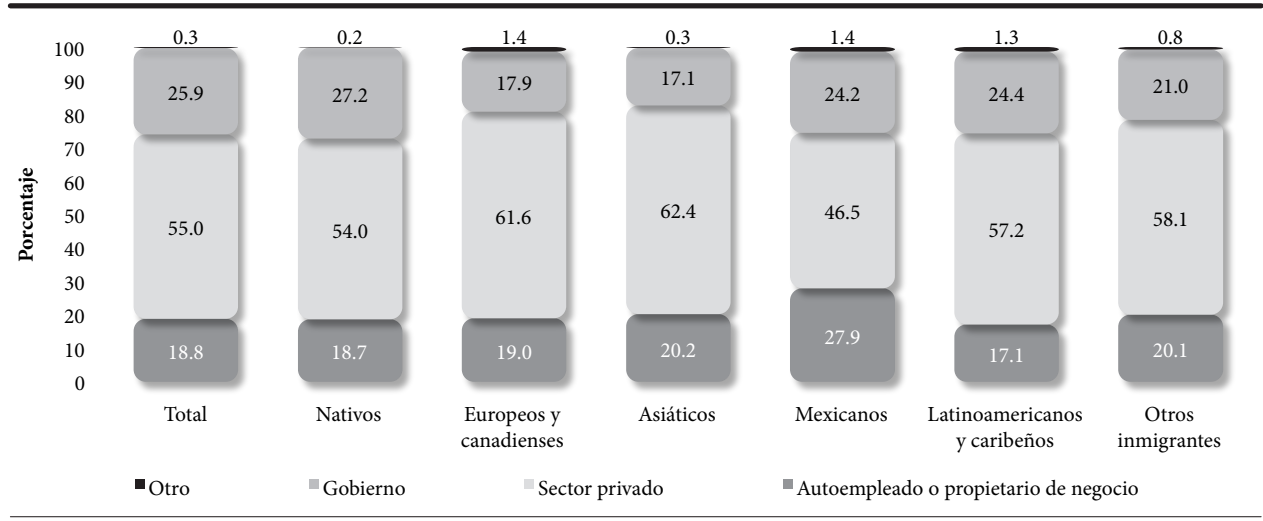

Fuente: Elaboración propia con base en NSCG, 2015.

\section{Ingresos por trabajo}

En este último apartado se analiza el ingreso por trabajo de los migrantes calificados mexicanos en perspectiva comparada con otros profesionales que participan en el mercado laboral estadounidense, a fin de identificar algunas diferencias y similitudes según origen nacional. En cuanto al ingreso promedio anual por trabajo de la población que trabaja tiempo completo (más de 35 horas a la semana), los datos de la encuesta revelan que los mexicanos son los peor remunerados del con- 


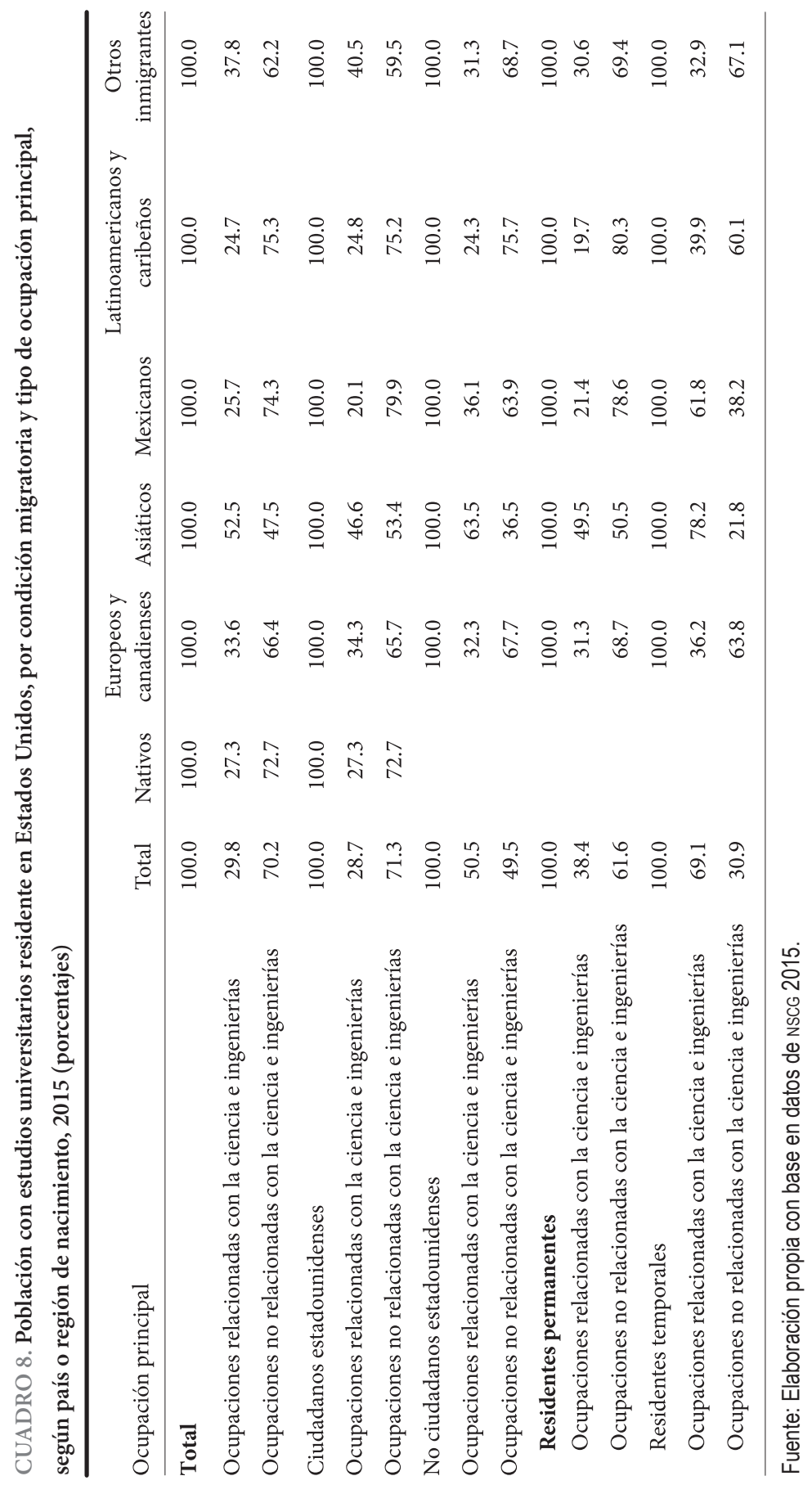


junto de profesionistas residentes en ese país, ya que perciben un ingreso promedio anual por debajo de la media nacional, y mucho menor que el de los nativos y otros profesionistas migrantes, e incluso inferior al de los procedentes de otros países de América Latina y el Caribe (véase gráfica 3), lo cual es consistente con los resultados plasmados en la literatura sobre el tema.

GRÁFICA 3. Ingreso promedio anual en dólares de la población con estudios universitarios residente en Estados Unidos, según país o región de nacimiento, 2015

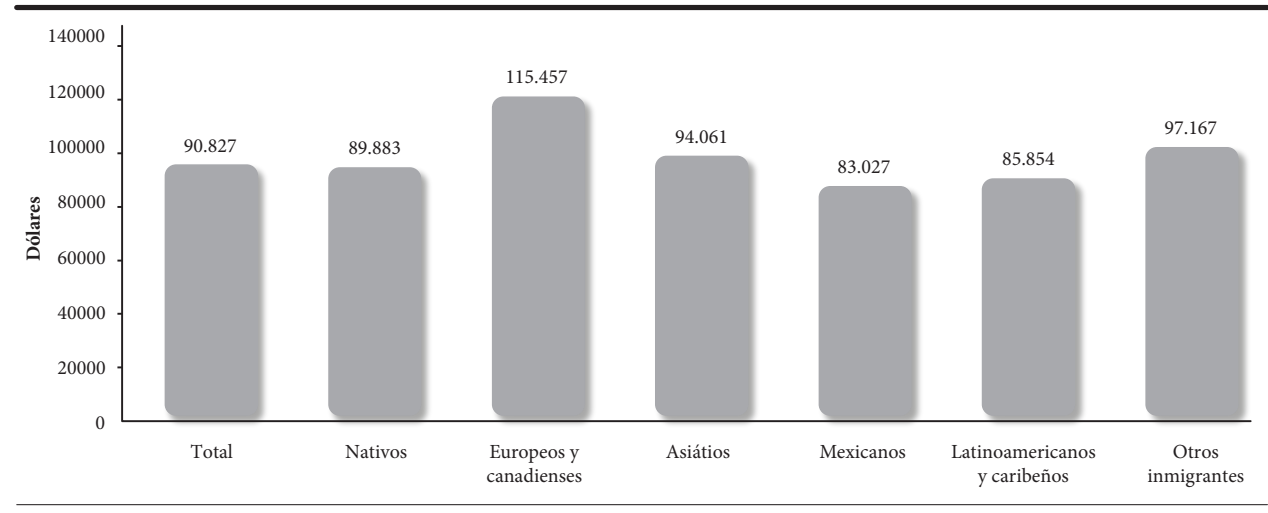

Fuente: Elaboración propia con base en NSCG, 2015.

A fin de profundizar en las diferencias salariales de los profesionistas en Estados Unidos, se estimó el ingreso por hora y la brecha salarial por hora de los nativos con respecto a los migrantes. Las brechas de ingreso indican qué tanto más o cuánto menos ganan los nativos respecto de los mexicanos y otros profesionales migrantes. En cuanto al ingreso promedio por hora, se encontró que para los mexicanos es de 40 dólares y se encuentra por debajo del obtenido por los nativos y otros migrantes; esto confirma que los mexicanos constituyen el grupo de profesionistas peor remunerados en el mercado laboral estadounidense. La brecha salarial respecto a los nativos es de $7.6 \%$, lo cual indica que por cada dólar que gana un profesionista nativo, un mexicano gana 0.924 dólares. Por el contrario, los europeos y canadienses, así como los asiáticos y los profesionales incluidos en la categoría de otros inmigrantes, obtienen un ingreso superior al de los nativos (véase cuadro 9 , siguiente página). 
CUADRO 9. Ingreso promedio anual en dólares de la población con estudios universitarios residente en Estados Unidos, según país o región de nacimiento, 201

\begin{tabular}{|c|c|c|c|c|c|c|c|}
\hline & Total & Nativos & $\begin{array}{l}\text { Europeos y } \\
\text { canadienses }\end{array}$ & Asiáticos & Mexicanos & $\begin{array}{c}\text { Latinoamericanos } \\
\text { y caribeños }\end{array}$ & $\begin{array}{c}\text { Otros } \\
\text { inmigrantes }\end{array}$ \\
\hline $\begin{array}{l}\text { Ingreso } \\
\text { por hora }\end{array}$ & 43.7 & 43.2 & 55.5 & 45.2 & 39.9 & 41.3 & 46.7 \\
\hline $\begin{array}{l}\text { Brecha del salario } \\
\text { por hora }\end{array}$ & & & 28.5 & 4.6 & -7.6 & -4.5 & 8.1 \\
\hline
\end{tabular}

Fuente: Elaboración propia con base en datos de NScG 2015.

\section{Comentario final}

Este trabajo ha mostrado que entre 2003 y 2015 la población inmigrante con estudios universitarios residente en Estados Unidos ha tenido un ritmo de crecimiento significativamente mayor que el de la población nativa de ese país. Pese a que, en términos absolutos, la mayor contribución fue la de migrantes provenientes de países asiáticos (India y China), la participación de migrantes nacidos en Latinoamérica y el Caribe también fue muy significativa, incluida la de los mexicanos. El trabajo también mostró que los migrantes formados en áreas de ciencias, tecnología, ingenierías y matemáticas (Стім) son una población objetivo clave de las empresas y el gobierno de ese país, pues se trata de un sector de trabajadores que promueve la creación y adopción de nuevas tecnologías y, por tanto, de un mayor crecimiento económico y acumulación de riqueza. Estos hechos fortalecen la idea de que la presencia de inmigrantes extranjeros, particularmente mexicanos (con niveles cada vez más altos de escolaridad), contribuyen significativamente a elevar la productividad y el crecimiento económico de Estados Unidos (Peri, 2017).

El trabajo también mostró que las condiciones de inserción económica y social de los migrantes calificados en Estados Unidos son profundamente desiguales, situación que ubica a la población mexicana en los niveles más bajos de la estructura social y ocupacional no solo en comparación con la población nativa, sino también en relación con otros grupos de migrantes. Así, vemos que los migrantes calificados de México presentan la menor proporción de población con ciudadanía estadounidense, las tasas más altas de trabajo temporal y las menores tasas de ocupación entre los inmigrantes sin ciudadanía, situación que se agudiza entre los migrantes mexicanos con residencia temporal. A esto se agrega el hecho de que es el grupo nacional con los ingresos promedio más bajos y, por tanto, con las brechas salariales más pronunciadas en relación con la población nativa.

Lo anterior implica grandes desafíos para los países de origen de esta mano de obra calificada, tanto desde la perspectiva del desarrollo local/nacional como en el 
ámbito de las negociaciones en materia migratoria. En el caso de México, resulta imperativo no solo promover la incorporación de los egresados de instituciones de educación superior al aparato productivo nacional con salarios competitivos y condiciones laborales dignas, sino también promover una agenda de negociación en materia migratoria que reconozca ante todo el aporte de los migrantes al desarrollo económico y social de Estados Unidos, así como una incorporación acorde a sus conocimientos y con respeto a sus derechos humanos, sociales y laborales.

\section{Referencias}

Amaro, M. (2016). De la ilusión de la calificación al desencanto de la ocupación: un análisis integral de la devaluación del trabajo de hombres y mujeres migrantes calificados de México y Estados Unidos. Tesis de maestría en población y desarrollo, Falcultad Latinoamericana de Ciencias Sociales, sede México. Ciudad de México.

Antecol, H., Cobb-Clark, D. A. \& Trejo, S. J. (2003). Immigration policy and the skills of immigrants to Australia, Canada and the United States. Journal of Human Resources, 38(1), 192-218.

Ávila, J. L. (2015). Highly skilled Mexican women migrants to the United States. Voices of Mexico, 99, 107-110.

Bauder, H. (2003). 'Brain abuse', or the devaluation of immigrant labour in Canada. Antipode, 35(4), 669-717.

Becerril, G., Canales, A., Cruz, R. \& Ocampo, M. (2016). La migración calificada de América Latina en Estados Unidos y Chile: determinantes de su incorporación laboral. Huellas de la Migración, 1(1), 125-155.

Brown, S. K. \& Bean, F. D. (2006). Assimilation models, old and new: explaining a long-term process. Migration Policy Institute. Recuperado de http://www.migrationpolicy.org/ article/assimilation-models-old-and-new-explaining-long-term-process [15 de julio de 2017].

Cairns, D., Cuzzocrea, V., Briggs, D. \& Veloso, L. (2017). The consequences of mobility. Reflexivity, social inequality and the reproduction of precariousness in highly qualified migration. Cham, Suiza: Palgrave Macmillan.

Calva Sánchez, L. \& Alarcón Acosta, R. (2015). La integración laboral precaria de los migrantes mexicanos calificados en Estados Unidos al inicio del siglo xxi. Papeles de Población. 21(83), 9-39.

Cheng, L. \& Yang, P. Q. (1998). Global interaction, global inequality, and migration of the highly trained to the United States. The International Migration Review, 32(3), 626-653.

Costa, D. \& Rosenbaum, J. (2017). Temporary foreign workers by the numbers. New estimates by visa classification. Economic Policy Institute, March 7. Recuperado de http:// www.epi.org/files/pdf/120773.pdf [7 de agosto de 2017]. 
Cruz Piñeiro, R. \& Ruiz Ochoa, W. (2010). Migración calificada de mexicanos a Estados Unidos mediante visado preferencial. Papeles de Población, 16(66), 103-135.

Docquier, F., Lowell, B. L. \& Marfouk, A. (2009). A gendered assessment of highly skilled emigration. Population and Development Review, 35(2), 297-321.

Fernández, C. \& Ortega, C. A. (2008). Labor market assimilation of immigrants in Spain: employment at the expense of bad job-matches? Spanish Economic Review, 10, 83-107.

Finamore, J. \& Foley, D. (2017). Prevalence of certifications and licenses among the collegeeducated population in the United States. InfoBrief. Recuperado de https://www.nsf. gov/statistics/2017/nsf17312/nsf17312.pdf [15 de julio de 2017].

Gandini, L. \& Lozano, F. (2012). La migración mexicana calificada en perspectiva comparada: el caso de los profesionistas con posgrado en Estados Unidos. En Ramírez García, T. \& Castillo, M. A. (eds.), El estado de la migración: México ante los recientes desafíos de la migración internacional. Ciudad de México: Consejo Nacional de Población.

Green, C., Kler, P. \& Leeves, G. D. (2007). Immigrant overeducation: evidence from recent arrivals to Australia. Economics of Education Review, 26(4), 420-432.

Hanson, G. H. \& Slaughter, M. J. (2013). Talent, immigration, and U.S. economic competitiveness. Recuperado de https://gps.ucsd.edu/_files/faculty/hanson/hanson_publication_immigration_talent.pdf [10 de julio de 2017].

Hernández, E., Solís, R. \& Stefanovich, A. (2013). Panorama del mercado laboral de profesionistas en México. Diagnóstico (2000-2009) y prospectiva (2010-2020). Informe final. Ciudad de México: Asociación Nacional de Universidades e Instituciones de Educación Superior (ANUIES).

Hunt, J. (2011). Which immigrants are most innovative and entrepreneurial? Distinctions by entry visa. Journal of Labor Economics. 29(3), 417-457.

Lan, F., Hale, K. \& Rivers, E. (2015). Immigrants' growing presence in the U.S. science and engineering workforce: education and employment characteristics in 2013. Recuperado de https://www.nsf.gov/statistics/2015/nsf15328/nsf15328.pdf [1 de abril de 2017].

Langdon, D., McKittrick, G., Beede, D., Khan, B. \& Doms, M. (2011). stem: good jobs now and for the future, U.S. Department of Commerce. Recuperado de http://www.esa. doc.gov/sites/default/files/stemfinalyjuly14_1.pdf [21 de abril de 2017.

Lindley, J. (2009). The over-education of U.K. immigrants and minority ethnic groups: evidence from the labour force survey. Economics of Education Review, 28(1), 80-89.

Lozano, F. \& Ramírez García, T. (2015a). Obama’s immigration executive action and sTEM workers, Voices of Mexico, 99, 99-104.

Lozano, F. \& Ramírez García, T. (2015b). Subutilización de las capacidades de los profesionales mexicanos de las ciencias y la tecnología y su vínculo con la migración a los Estados. Notas de Población, 101, 157-186.

Lozano, F., Gandini, L. \& Ramírez García, T. (2015). Devaluación del trabajo de posgraduados en México y su relación con la migración internacional: el caso de los profesionistas en ciencia y tecnología. Migración y Desarrollo, 13(25), 61-89. 
Lozano, F. \& Gandini, L. (2010). Migrantes calificados de América Latina y el Caribe. ¿Capacidades desaprovechadas? Cuernavaca, México: Centro Regional de Investigaciones Multidisciplinarias de la Universidad Nacional Autónoma de México.

Mattoo, A., Neagu, I. \& Özden, Ç. (2008). Brain waste? Educated immigrants in the U.S. labor market. Journal of Development Economics, 87(2), 255-269.

National Science Foundation $(2003,2010,2015)$. National Survey of College Graduates. Recuperado de https://ncsesdata.nsf.gov/datadownload/ [3 de abril de 2017].

Pellegrino, A. \& Martínez, J. (2001). Una aproximación al diseño de políticas sobre migración internacional calificada en América Latina. Recuperado de http://repositorio. cepal.org/handle/11362/7158 [3 de abril de 2017].

Peri, G. (2017). Immigration and economic growth in the U.S., 2000-2015. EConofaCt. Immigration Policy. Recuperado de http://econofact.org/immigration-and-economicgrowth-in-the-u-s-2000-2015 [6 de abril de 2017].

Ramírez García, T. \& Lozano, F. (2015). Reinserción laboral de los migrantes calificados de retorno de Estados Unidos a México: ¿ganancia o desperdicio de talentos? En Lozano, F. \& Martínez, J. (eds.), Retorno en los procesos migratorios de América Latina. Conceptos, debates, evidencias. Montevideo: AlaP, UnfPA, oim, Trilce.

Ramírez García, T. \& Gandini, L. (2016). Trabajadoras calificadas: las mujeres mexicanas en el mercado de trabajo estadounidense en perspectiva comparada. Revista Latinoamericana de Población, 10(19), 33-56.

Ramírez García, T. \& Lozano, F. (2017). Selectividad y precariedad laboral en la migración calificada de América Latina y el Caribe, 2000-2010. Revista Interdisciplinar da Mobilidade Humana, 25(49), 113-134.

Salami, B. \& Nelson, S. (2014). The downward occupational mobility of internationally educated nurses to domestic workers. Nursing Inquiry, 21(2), 153-161.

Tuirán, R. \& Ávila, J. L. (2013). ¿De la fuga a la circulación de talentos? Este País. Recuperado de http://archivo.estepais.com/site/2013/de-la-fuga-a-la-circulacion-de-talentos/ [15 de julio de 2017].

Woo Morales, O. (2001). Las mujeres también nos vamos al Norte. Guadalajara: Universidad de Guadalajara. 